\title{
PERILAKU ANAK SEKOLAH DASAR TENTANG KEBIASAAN MENCUCI TANGAN DI SEKOLAH DASAR NEGERI 113 KOTA PEKANBARU
}

\author{
Tri Siwi KN, Novita K \\ Fakultas MIPA dan Kesehatan Universitas Muhammadiyah Riau \\ Email: trisiwiningrum@gmail.com
}

\begin{abstract}
ABSTRAK
Mencuci tangan merupakan teknik yang sangat mendasar dalam mencegah dan mengendalikan infeksi. Dengan mencuci tangan dapat menghilangkan sebagian besar mikroorganisme yang ada di kulit. Tujuan Penelitian ini untuk mengetahui Perilaku Anak Sekolah Dasar Tentang Kebiasaan Mencuci Tangan Di Sekolah Dasar Negeri 113 Kota Pekanbaru. Jenis Penelitian yang digunakan adalah deskriptif dengan teknik pengambilan sampel Random Sampling yang berjumlah 73 responden. Alat pengumpulan data menggunakan kuesioner dan analisa data yang digunakan adalah univariate. Hasil penelitian menunjukkan bahwa Perilaku Anak Sekolah Dasar Negeri 113 Kota Pekanbaru pada anak Sd mayoritas dalam kategori baik yaitu sebanyak 44 responden (60,27 \%). Berdasarkan hasil penelitian tersebut diharapkan pada siswa-siswi dapat mempertahankan kebiasaan mencuci tangan di sekolah maupun di rumah sehingga membiasakan pola hidup sehat agar dapat terhindar dari penyakit infeksi.
\end{abstract}

Kata Kunci: Perilaku, Anak SD, Kebiasaan Mencuci Tangan

\section{PENDAHULUAN}

Masa anak-anak pada hakikatnya merupakan aset terpenting dalam tercapainya keberhasilan suatu negara, karena merupakan generasi penerus bangsa selanjutnya. Derajat kesehatan anak pada saat ini belum bisa dikatakan baik karena masih banyak terdapat masalah kesehatan khususnya pada anak sekolah. Anak usia sekolah merupakan kelompok usia yang kritis karna pada usia tersebut rentan terhadap masalah kesehatan sehingga bisa mengalami berbagai penyakit yang berkaitan dengan system pencernaan, hal ini sangat berkaitan erat dengan kebiasaan dan perilaku anak yang berkaitan dengan perilaku kesehatan (Gobel, 2009).

Prilaku kesehatan pada anak di sekolah yang harus diperhatikan adalah pola sarapan anak, kebersihan kuku, dan kebiasaan jajanan di tempat sembarangan dengan jajanan yang ratarata tidak sehat dan juga kebiasaan mencuci tangan (Syamsu, 2002).

Mencuci tangan dengan sabun adalah salah satu cara paling efektif untuk mencegah penyakit diare dan ISPA, keduanya menjadi penyebab utama kematian anak. Setiap tahun, sebanyak 3,5 juta anak di seluruh dunia meninggal sebelum mencapai umur lima tahun karena penyakit diare dan ISPA, mencuci tangan dengan sabun juga dapat mencegah infeksi kulit, mata, kecacingan, dan flu burung (Nuryanti, 2008).

Kebiasaan anak Indonesia dalam mencuci tangan pakai sabun hingga kini masih tergolong rendah kuman yang ada dimanapun, mencuci tangan merupakan salah satu cara untuk menghilangkan kuman dan untuk menghindari penularan penyakit. disekolah anak tidak hanya belajar, tetapi banyak kegiatan lain yang dapat dilakukan oleh anak di sekolah seperti bermain, bersentuhan ataupun bertukar barang-barang dengan teman-teman. Kuman yang ada di alatalat tulis, kalkulator, buku-buku dan bendabenda lain akan dengan mudah berpindah dari tangan satu anak ke anak lainnya, sehingga jika ada anak yang mempunyai penyakit tertentu akan mudah menular pada anak lainnya. Sehingga, mencuci tangan harus dilatih sejak dini pada anak agar anak memiliki kebiasaan mencuci tangan, sehingga anak terhindar dari penyakit (Djauzi, 2008).

WHO telah merencanakkan setiap tanggal 15 Oktober sebagai hari mencuci tangan pakai sabun sedunia, yang diikuti oleh 20 negara di dunia, salah satu diantaranya adalah Indonesia (Tazrian, 2011). 
Sekolah merupakan tempat yang strategis dalam kehidupan anak, maka sekolah dapat difungsikan secara tepat sebagai salah satu institusi yang dapat membantu dan berperan dalam upaya optimalisasi tumbuh kembang anak usia sekolah dengan upaya promotif dan preventif, salah satunya penerapan gerakan mencuci tangan pakai sabun pada anak usia sekolah (Notoatmodjo, 2010).

\section{METODOLOGI PENELITIAN}

Jenis Penelitian yang digunakan adalah deskriptif dengan teknik pengambilan sampel random Sampling yang berjumlah 73 responden. Alat pengumpulan data menggunakan kuesioner dan analisa data yang digunakan adalah univariate. Teknik pengambilan "random sampling”. tersebut menggunakan rumus :

$$
\mathrm{n}=\frac{\mathrm{N}}{1+\mathbb{N}\left(\mathrm{d}^{2}\right)}
$$

Keterangan:

$\mathrm{N}=$ Besar Populasi

$\mathrm{n}=$ Besar Sampel

$\mathrm{d}=$ Tingkat Kepercayaan $(90 \%)$

$\mathrm{n}=\frac{\mathrm{N}}{1+\mathrm{N}\left(\mathrm{d}^{2}\right)}$

$\mathrm{n}=\frac{276}{1+276\left(0,1^{2}\right)}$

$\mathrm{n}=\frac{276}{1+276(0,01)}$

$\mathrm{n}=\frac{276}{1+2,76}$

$\mathrm{n}=\frac{276}{3.76}$

$\mathrm{n}=73$ siswa

Dalam penelitian ini teknik pengumpulan data yang dilakukan adalah melalui data Primer yang dilakukan dengan cara menyebarkan lembar kuesioner dan data sekunder berupa data yang berkaitan dengan masalah yang diteliti, internet, dan data-data lain yang mendukung dokumentasi yang diperoleh dari Sekolah Dasar Negeri 113 Kota Pekanbaru.

\section{Pengertian Perilaku}

Perilaku merupakan tindakan atau perbuatan suatu organisme yang dapat diamati dan bahkan dapat dipelajari. Perilaku tidak sama dengan sikap. Sikap adalah hanya suatu kecenderungan untuk mengadakan tindakan pada suatu objek, dengan suatu cara yang menyatakan adanya suatu tanda-tanda untuk menyenangi atau tidak menyenangi objek tersebut (Notoatmodjo, 2005).

Faktor - faktor Yang Mempengaruhi Perilaku Kesehatan

Perilaku kesehatan itu sendiri juga dipengaruhi oleh 3 faktor, yaitu:

a. Faktor-Faktor Predisposisi (Predisposing Factor)

Yang terwujud dalam pengetahuan, sikap, kepercayaan, keyakinan, nilai-nilai dan sebagainya.

1) Pengetahuan: merupakan hasil dari tahu, dan ini terjadi setelah orang melakukan penginderaan terhadap suatu objek tertentu. Penginderaan terjadi melalui panca indra manusia, yakni indera penglihatan, pendengaran, penciuman, rasa dan raba. Sebagian besar manusia diperoleh melalui mata dan telinga.

2) Sikap:merupakan penilaian (bisa berupa pendapat) seseorang terhadap stimulus dan objek (dalam hal ini adalah masalah kesehatan, termasuk penyakit).

3) Kepercayaan: Sering diperoleh dari guru, orangtua dan seseorang yang dituakan. Pendidikan kesehatan bisa melalui guru atau orang tua, misal selain mengajari cara mencuci tangan guru atau orangtua bisa membiasakan dirinya mencuci tangan sehingga anak bisa meniru kebiasaan yang dilakukan guru atau orang tuanya..

b. Faktor-faktor pemungkin (enabling factor) :Terwujud dalam lingkungan fisik, ketersediaan sarana dan prasarana atau fasilitas kesehatan bagi masyarakat.

c. Faktor-faktor Penguat (reinforcing faktor):Terwujud dalam sikap dan perilaku petugas kesehatan, atau petugas yang lain, 
yang merupakan kelompok referensi dari perilaku masyarakat.

\section{Pengertian Cuci Tangan}

Mencuci tangan adalah teknik yang sangat mendasar dalam mencegah dan mengendalikan infeksi, dengan mencuci tangan dapat menghilangkan sebagian besar mikroorganisme yang ada di kulit (Hidayat, 2005).

\section{Tujuan dan Manfaat Mencuci Tangan}

1) Mencegah terjadinya infeksi melalui tangan.

2) Membantu menghilangkan mikroorganisme yang ada di tangan

3) Waktu mencuci tangan

Sebelum makan,sesudah dari kamar kecil, sepulang pergi sekolah, sesudah memegang barang kotor, uang dan hewan

4) Teknik Mencuci Tangan Yang Benar.

Menurut ( Kamaruddin, 2009) teknik mencuci tangan yang benar

1. Setelah diberi sabun pada telapak tangan, gosoklah kedua telapak tangan secara bergantian, sehingga kedua telapak tangan rata dengan sabun

2. Telapak kanan diatas punggung tangan kiri dan telapak kiri diatas punggung tangan kanan gosok kedua punggung tangan secara bergantian dan, gosok diantara jari jemari tangan secara bergantian sehingga terkena sabun

3. Telapak dengan telapak dan jari saling terkait gosok kedua telapak tangan dan diantara jari jemari secara bergantian sehingga kena sabun

4. Letakkan punggung jari pada telapak satunya dengan jari saling mengunci gosok punggung jari yang saling mengunci pada telapak satunya, secara bergantian.

5. Jempol kanan digosok memutar oleh telapak kiri \& sebaliknya gosok jempol, dan jari jari tangan lainnya, secara memutar bergantian di kedua tangan.

6. Jari kiri menguncup, gosok memutar ke kanan \& ke kiri pada telapak kanan \& sebaliknya gosok gosoklah ujung-ujung kuku pada telapak tangan, sehingga busa sabun masuk kedalam sela sela kuku,secara bergantian di kedua tangan.

7. Pegang pergelangan tangan kiri dengan tangan kanan \& sebaliknya, gerakan memutar gosok pergelangan tangan secara memutar dari pergelangan tangan sampai siku secara bergantian.

8. Setelah selesai siramlah kedua tangan dengan air yang mengalir, dengan kran air atau dengan air mengalir menggunakan gayung. Setelah selesai keringkan kedua tangan dengan kain kering dan bersih.

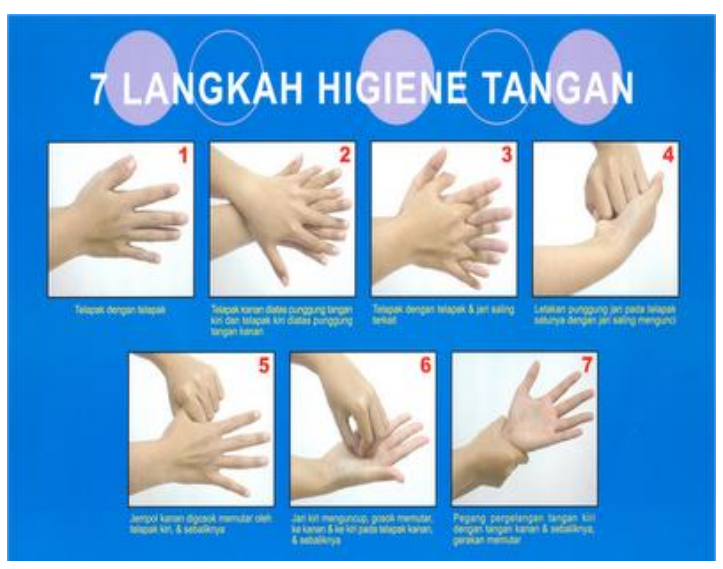

Gambar 1 Langkah cuci tangan dengan benar

\section{HASIL DAN PEMBAHASAN}

Berdasarkan penelitian yang dilakukan diperoleh data-data mengenai tentang perilaku anak sekolah dasar tentang kebiasaan mencuci tangan sebagai berikut:

Tabel 1. Distribusi Frekuensi Berdasarkan Kelas Responden di Sekolah Dasar Negeri 113 Kota Pekanbaru Mei 2015

\begin{tabular}{llll}
\hline No & Kategori kelas & $\begin{array}{l}\text { Frekuensi } \\
\text { (f) }\end{array}$ & $\begin{array}{l}\text { Persentase } \\
(\mathbf{\%})\end{array}$ \\
\hline 1 & IV(Empat) & 22 & 30,13 \\
2 & V (Lima) & 31 & 42,47 \\
3 & VI (Enam) & 20 & 27,40 \\
\hline & Total & $\mathbf{7 3}$ & $\mathbf{1 0 0}$ \\
\hline
\end{tabular}

Berdasarkan Tabel 1 kelas responden di Sekolah Dasar Negeri 113 Kota Pekanbaru mayoritas kelas $\mathrm{V}$ yaitu sebanyak 31 responden $(42,47 \%)$. 
Tabel 2. Distribusi Frekuensi Berdasarkan Umur Responden di Sekolah Dasar Negeri 113 Kota Pekanbaru Mei 2015

\begin{tabular}{llll}
\hline No & $\begin{array}{l}\text { Kategori } \\
\text { Umur } \\
\text { (Tahun) }\end{array}$ & $\begin{array}{l}\text { Frekuensi } \\
\text { (f) }\end{array}$ & $\begin{array}{l}\text { Persentase } \\
(\boldsymbol{\%})\end{array}$ \\
\hline 1 & Umur $(7-9)$ & 5 & 6,85 \\
2 & Umur $(10-12)$ & 68 & 93,15 \\
\hline & Total & $\mathbf{7 3}$ & $\mathbf{1 0 0}$ \\
\hline
\end{tabular}

Berdasarkan Tabel 2 umur responden di Sekolah Dasar Negeri 113 Kota Pekanbaru mayoritas berumur 10 -12 tahun yaitu sebanyak 68 responden $(93,15 \%)$

Tabel 3. Distribusi Frekuensi Responden berdasarkan Jenis Kelamin di Sekolah Dasar Negeri 113 Kota Pekanbaru Mei 2015

\begin{tabular}{llll}
\hline No & $\begin{array}{l}\text { Kategori } \\
\text { Jenis } \\
\text { Kelamin }\end{array}$ & $\begin{array}{l}\text { Frekuensi } \\
(\mathbf{f})\end{array}$ & $\begin{array}{l}\text { Persentase } \\
(\boldsymbol{\%})\end{array}$ \\
\hline 1 & Laki-laki & 31 & 42,47 \\
2 & Perempuan & 42 & 57,53 \\
\hline & Total & $\mathbf{7 3}$ & $\mathbf{1 0 0}$ \\
\hline
\end{tabular}

Berdasarkan Tabel 3 dapat diketahui bahwa jenis kelamin responden di Sekolah Dasar Negeri 113 Kota Pekanbaru mayoritas berjenis kelamin perempuan yaitu sebanyak 42 responden $(57,53 \%)$.

Tabel 4. Distribusi Frekuensi Responden Berdasarkan Informasi yang Pernah Diperoleh di Sekolah Dasar Negeri 113Kota Pekanbaru Mei 2015

\begin{tabular}{llll}
\hline No & $\begin{array}{l}\text { Informasi } \\
\text { yang } \\
\text { diperoleh }\end{array}$ & $\begin{array}{l}\text { Frekuensi } \\
\text { (f) }\end{array}$ & $\begin{array}{l}\text { Persentase } \\
(\mathbf{\%})\end{array}$ \\
\hline 1 & Ya & 40 & 54,79 \\
2 & Tidak & 33 & 45,21 \\
\hline & Total & $\mathbf{7 3}$ & $\mathbf{1 0 0}$ \\
\hline
\end{tabular}

Berdasarkan Tabel 4 dapat diketahui bahwa mayoritas responden pernah mendapatkan informasi tentang perilaku anak sekolah dasar tentang kebiasaan mencuci tangan di Sekolah
Dasar Negeri 113 Kota Pekanbaru adalah sebanyak 40 responden $(54,79 \%)$.

Tabel 5. Distribusi Frekuensi Responden Berdasarkan Sumber Informasi di Sekolah Dasar Negeri 113 Kota Pekanbaru Mei 2015

\begin{tabular}{llll}
\hline No & $\begin{array}{l}\text { Sumber } \\
\text { Informasi }\end{array}$ & $\begin{array}{l}\text { Frekuensi } \\
(\mathbf{f})\end{array}$ & $\begin{array}{l}\text { Persentase } \\
(\boldsymbol{\%})\end{array}$ \\
\hline \multirow{4}{*}{$\begin{array}{l}\text { Media } \\
2\end{array}$} & Cetak & 10 & 25,00 \\
3 & Media & 7 & 17,50 \\
4 & Elektronik & 3 & 7,50 \\
4 & Tenaga & 20 & 50,00 \\
& Kesehatan & & \\
& Guru & & \\
\hline & Total & $\mathbf{4 0}$ & $\mathbf{1 0 0}$ \\
\hline
\end{tabular}

Berdasarkan Tabel 5 diketahui hasil bahwa sumber informasi mayoritas yang di peroleh responden di Sekolah Dasar Negeri 113 Kota Pekanbaru adalah dari Guru sebanyak 20 responden $(50,00 \%)$.

Tabel 6. Distribusi Frekuensi Responden Berdasarkan Perilaku di Sekolah Dasar Negeri 113 Kota Pekanbaru Mei 2015

\begin{tabular}{llll}
\hline No & $\begin{array}{l}\text { Kategori } \\
\text { Perilaku }\end{array}$ & $\begin{array}{l}\text { Frekuensi } \\
\text { (f) }\end{array}$ & $\begin{array}{l}\text { Persentase } \\
(\boldsymbol{\%})\end{array}$ \\
\hline 1 & Baik & 44 & 60,27 \\
2 & Tidak Baik & 29 & 39,73 \\
\hline & Total & $\mathbf{7 3}$ & $\mathbf{1 0 0}$ \\
\hline
\end{tabular}

Berdasarkan Tabel 6 dapat diketahui bahwa perilaku anak sekolah tentang kebiasaan mencuci tangan responden di Sekolah Dasar Negeri 113 Kota Pekanbaru mayoritas berkategori baik yaitu sebanyak 44 responden $(60,27)$.

Menurut Wong (2004), dalam Rosyidah (2014) "Hubungan Cuci Tangan Terhadap Kejadian Diare Pada Siswa Di Sekolah Dasar Negeri Ciputat 02", dalam hasil penelitian mengenai waktu responden diajarkan mencuci tangan dari Tk sampai Sd sebanyak 21,4 persen, tidak pernah diajarkan mencuci tangan sebanyak 
19.6 persen, anak usia sekolah dasar mempunyai memori jangka pendek yang telah berkembang dengan baik, akan tetapi memori jangka panjang masih sangat terbatas untuk mengurangi keterbatasan tersebut, anak berusaha menggunakan strategi memori dengan bentuk perilaku.

Teori di atas didukung hasil penelitian Rosidi (2010). "Hubungan Kebiasaan Cuci Tangan Dan Sanitasi Makanan Dengan Kejadian Diare Pada Anak Sd Negeri Podo 2 Kecamatan Kedungwuni Kabupaten Pekalongan”. Dalam hasil penelitian memperoleh hasil sebagian besar anak SD mempunyai kebiasaan mencuci tangan sebanyak 94 persen, sedangkan yang tidak biasa mencuci tangan 6 persen, sehingga 100 persen responden yang mempunyai perilaku kebiasaan mencuci tangan yang tidak mengalami kejadian diare.

Dengan demikian peneliti berpendapat bahwa dengan adanya usaha responden untuk membiasakan melakukan mencuci tangan dalam kehidupan sehari-hari, sehingga kejadian diare yang terjadi pada anak SD cenderung berkurang karena kebiasaan anak SD yang mayoritas telah melakukan cuci tangan.

Berdasarkan hasil penelitian, responden mayoritas di kelas $\mathrm{V}$ yaitu sebanyak 31 responden (42,47\%). Berdasarkan umur responden mayoritas berumur $10-12$ tahun yaitu sebanyak 68 responden $(93,15 \%)$. Berdasarkan informasi yang diperoleh mayoritas responden mendapatkan informasi sebanyak 40 responden $(54,79 \%)$. Berdasarkan sumber informasi responden mayoritas responden mendapatkan sumber informasi yang pernah di peroleh berasal dari guru yaitu sebanyak 20 responden $(50,00 \%)$. Serta hasil penelitian yang diperoleh dapat disimpulkan bahwa anak SD yang berperilaku mencuci tangan dalam kategori baik yaitu sebanyak 44 responden $(60,27 \%)$.

Penelitian Cahyani (2010), dalam Rosyidah (2014). "Hubungan Cuci Tangan Terhadap Kejadian Diare Pada Siswa Di Sekolah Dasar Negeri Ciputat 02". Dalam hasil penelitian Sumber informasi yang dapat mempengaruhi perilaku mencuci tangan seseorang sehingga seseorang dapat melakukan cuci tangan yang benar. Hasil penelitian yang di mendapat informasi dari orang tua sebanyak 88.5 persen, dari sekolah sebanyak 66,7 persen, dari media sebanyak 56,8 persen. Selain itu, siswa yang mendapat informasi dari orang tua cenderung dua kali lebih benar dalam mencuci tangan dibandingkan dengan tidak mendapat informasi dari orang tua.

\section{KESIMPULAN DAN SARAN}

Dengan demikian peneliti berasumsi bahwa dengan adanya pendidikan kesehatan yang diberikan oleh guru-guru yang biasanya dilakukan setiap seminggu sekali setiap selesai berolah raga. Perilaku cuci tangan tidak akan serta merta terbentuk pada anak, tanpa ada kebiasaan sejak dini. Penekanan pentingnya cuci tangan pada anak SD perlu dilakukan secara terus menerus sehingga akan terbentuk kebiasaan cuci tangan tanpa harus diingatkan lagi. Pihak sekolah diharapkan dapat memberikan motivasi pada seluruh siswa untuk dapat melakukan cuci tangan dengan menggunakan sabun ketika di lingkungan sekolah dan di rumah, yang bertujuan untuk mencegah timbulnya penyakit yang disebabkan oleh tangan yang kotor, dan keberhasilan cuci tangan dengan menggunakan sabun bukan hanya ditunjang oleh perilaku cuci tangan saja, namun juga oleh adanya sarana dan prasarana yang diperlukan dalam menjaga keberlangsungan kegiatan cuci tangan.

Menurut hasil penelitian ini, peneliti juga berpendapat bahwa banyaknya informasi responden, akan berpengaruh perilaku responden dalam proses mencuci tangan khususnya pada anak sekolah. Karena dalam hal ini responden harus memiliki informasi usaha untuk memberikan stimulasi yang tepat sehingga anak dapat berperilaku hidup sehat secara optimal.

\section{DAFTAR PUSTAKA}

Buku Saku Rumah Tangga Sehat Dengan PHBS, Pusat Promosi Kesehatan,Depkes RI, Jakarta, 2007, Hal.2).

Djauzi, S. (2008). Raih Kembali Kesehatan Mencegah Berbagai Penyakit Hidup 
Sehat Untuk Keluarga. Jakarta: Kompas.

Depkes. (2010). Buku Panduan Peringatan Hari Cuci Tangan Sedunia, Ketiga. Jakarta.

Hajar dan Misnaniati. (2011). Hubungan Pengetahuan dan Sikap Terhadap Perilaku Cuci Tangan Pakai Sabun Pada Masyarakat Di Desa Seniro Timur. Jurnal Pembangunan Manusia Volume 5 Nomor 1.

Hidayat, A.Aziz Alimul. (2009). Pengantar Ilmu Keperawatan Anak. Jakarta: Salemba Medika.

Parmanda, K. (2013). Gambaran Pengetahuan Masyarakat Tentang Manfaat Bekam Bagi Kesehatan. Pekanbaru.

Setiadi. (2007). Konsep dan Penulisan Riset Keperawatan. Yogyakarta: Graha Ilmu.

Wati (2010). Pendidikan Kesehatan Dalam Keperawatan. Jakarta: EGC.

Tarwoto, Wartonah. (2004). Kebutuhan Dasar

Manusia dan Proses Keperawatan. Jakarta: Salemba Medika.

Budiman. (2011) . Penelitian Kesehatan. Bandung : Refika Aditama.

Notoatmodjo, Soekidjo. (2005). Metodologi Penelitian Kesehatan. Jakarta: PT Reneka Cipata.

Notoatmodjo, S. (2010), Perilaku Pendidikan dan Perilaku Kesehatan.Jakarta. Rineka Cipta
Tazrian (2011), Promkes Dan Teori Aplikasi. Cetakan Pertama. Jakarta : Rineka Cipta.

Kamaruddin, (2009), teknik mencuci tangan yang benar. Jakarta: EGC

Nursalam, (2003). Konsep dan penerapan meteologi penelitian ilmu keperawatan.

Jakarta: salemba medika.

Rosyidah, (2014), hubungan cuci tangan terhadap kejadian diare pada siswa di sekolah dasar negeri ciputat 02 .proses studi ilmu keperawatan fakultas kedokteran dan ilmu kesehatan universitas islam negeri syarif hidayatullah Jakarta.

Rosidi, (2010), Hubungan kebiasaan cuci tangan dan sanitasi makanan dengan

Kejadian diare pada anak sd negeri podo 2 kecamatan Kedungwuni kabupaten pekalongan. Program Studi DIII Gizi Fakultas Ulmu Keperawatan dan Kesehatan Universitas Muhammadiyah, Semarang.

Anggrahitha, Resti (2009), Studi intervensi peningkatan perilaku hidup bersih dan sehat bagi anak SDN cisalak 1 depok. fakultas kesehatan masyarakat universitas Indonesia. Depok. 